\title{
Outcome of surgical management of late presenting developmental dysplasia of hip with pelvic and femoral osteotomies
}

\author{
G. Jagadesh ${ }^{1}$, Venugopal S $M^{2, *}$, SSRK Chaitanya $\mathbf{B}^{3}$, Karthik Gudaru ${ }^{4}$ \\ ${ }^{1} \mathrm{HOD},{ }^{2-4}$ Assistant Professor, Dept. of Orthopaedics, Balaji Institute of Surgery, Research and Rehabilitation for the \\ Disabled (BIRRD) Hospital Tirupati, Andhra Pradesh, India
}

*Corresponding Author:

Email: shring31@gmail.com

\begin{abstract}
Introduction: Patients with Developmental dysplasia of hip many a times present later in the age due to missed or delayed diagnosis. The treatment of DDH is mainly dependent upon the age of the child at the time of presentation and varies according to it. In the late presenting cases it is mostly surgical with open reduction alone or in combination with pelvic and femoral osteotomies.

Materials and Methods: This study between October 2012 and October 2014 includes 21 patients with unilateral dysplastic hips, surgically treated with a single stage procedure of open reduction and Acetabuloplasty of Pemberton, along with Varus derotation osteotomy and femoral shortening when necessary. Preoperatively they were classified according to Tonnis grade. Clinical assessment was done using Modified McKay's criteria; Radiological evaluation was done using Severin's radiographic criteria.

Results: The mean follow up period was 15.14 months and the mean age at surgery was 66.86 months. McKay's grades were excellent in 8 hips, good in 11 hips, fair in 1 hip and poor in 1 hip. Severin's score was excellent in 4 hips, good in 15 hips, fair in 1 hip and poor in 1 hip.

Conclusions: Every case of DDH is unique. The type of surgery chosen depends on the clear understanding of each hip after using the available resources. The combination of open reduction with pelvic and/ or femoral osteotomy when needed gives good immediate stability and promotes remodelling. This surgery is a technically demanding procedure but when performed properly by an experienced surgeon, it does give satisfactory results.
\end{abstract}

Keywords: Developmental dysplasia of hip, Late presentation, Open reduction, Pelvic and/ or femoral osteotomy.

\section{Introduction}

Developmental dysplasia of the hip includes acetabular dysplasia and femoral head dislocation or subluxation ". "Dysplastic acetabulum" is a term now generally accepted, and means a congenital and genetic anomaly of the acetabulum, with hip-joint instability and incongruity. In neglected CDH the femoral head is small and non-spherical, and has migrated a variable distance proximally and posteriorly to a hollow on the iliac wing, the false acetabulum. The femoral neck shows increased anteversion and the lesser trochanter lies more anteriorly than normal. The femur is generally hypoplastic with a very narrow canal. The original acetabulum is also hypoplastic and shallow with a narrow opening, while the anterior and especially the medial wall are soft with poor bone stock. ${ }^{2}$ True acetabulum is filled with fibrofatty tissue known as pulvinar and the labrum is hypertrophied and inverted.

Treatment of congenital dislocation of the hip is perhaps more clearly age related than any other condition in medicine, a fact that reflects progression of secondary pathologic changes. In an infant with dislocatable hips due to ligamentous laxity, simple abduction splinting by any of several devices will almost invariably result in a normal hip. Such treatment is considered best prophylactic. Opinions vary on details and a review of the literature suggests that there are no hard data on precisely when conservative management ceases to be appropriate. Between the ages of 6 and 12 months, manipulation under anaesthesia may be required to attain reduction. This should be followed by a period of immobilization in a cast in the position of maximal stability. Open reduction enjoys some advocacy before 2 years of age, and is increasingly used in those over 2 years old. It is currently combined with osteotomy of the innominate bone, and sometimes with derotational osteotomy of the proximal femoral diaphysis to correct anteversion. ${ }^{3}$

The goal of treatment of developmental dysplaia of hip is to achieve a well aligned congruous joint that is stable and has a painless restoration of full range of motion and function. At our centre to achieve the above goal, surgeon used open reduction of hip by femoral shortening if required in higher dislocations, varus derotation osteotomy in case of rotational deformity of proximal femur, pemberton's acetabuloplasty in case of increased acetabular index, capsuloraphy to correct the lax capsule and the patient is immobilised in a hip spica cast for 3 months.

\section{Materials and Methods}

The study was conducted from October 2012 to October 2014 and included 21 patients with neglected unilateral developmental dysplasia of hip who were surgically treated in department of orthopaedics, BIRRD hospital, Tirupati. There were 7 males and 14 females in the study between the age group of 25 months and 96 months. In 11 patients the right hip was 
involved and in 10 patients it was the left hip. All these patients underwent surgery with open reduction and pembertons acetabuloplasty, femoral varus derotation osteotomy was done in 5 cases and varus derotation osteotomy along with femoral shortening was done in 7 cases.

Preoperative radiographic evaluation included examination of plain radiographs to classify patients according to the Tonnis classification system ${ }^{4}$ (Table 1) to assess the degree of dislocation of the femoral head. Other radiological indices like Acetabular Index (AI) and Femoral Neck Shaft Angle (FNSA) were also measured. Range of motion of the affected hip and limb length discrepancy were also noted.

Post operatively radiographs were taken at regular follow ups and radiological evaluation was done using severin's radiographic criteria ${ }^{5}$ (Table 2 ) by measuring center edge angle of wiberg. Acetabular index and femoral neck shaft angle were also calculated. Clinical evaluation of the patient was also done at every follow up by modified McKay's criteria ${ }^{6}$ (Table 3 ). The patient was examined for stability of the hip, range of motion of the hip, Trendelenburg sign, gait and limb length discrepancy.

\section{Operative Procedure}

Surgery was performed with patient supine on a radiolucent operating table under general anaesthesia under control of c-arm image intensifier.

The surgical procedure began with an Adductor tenotomy followed by the lateral approach to the hip. A longitudinal skin incision is made that starts from $5 \mathrm{~cm}$ proximal to the tip of greater trochanter and extends down the line of shaft of femur for about $8 \mathrm{~cm}$. The underlying subcutaneous fat and deep fascia were incised in line with the skin incision and anterior fibres of gluteus medius were exposed. Anterior fibres of gluteus medius were detached and raised as an anterior flap which was later sutured back. The underlying gluteus minimus was retracted to visualise the joint capsule. An inverted T shaped incision was made on the capsule and femoral head was exposed. Iliopsoas tendon was released from the lesser trochanter.

Once the acetabulum was exposed, excision of pulvinar and hypertrophied inverted labrum was done. Ligamentum teres and transverse acetabular ligament were also released. Shortening of the femur was reserved for cases in which relocation of hip was not possible or there was increased pressure on the femoral head after relocation. The femoral shortening was done at the region of lesser trochanter. The amount of capital femoral epiphysis overlying the ilium was calculated to determine the amount of femoral shaft to be resected. The osteotomy was then fixed with a four to seven holed plate according to the age of patient and size of the femur. A varus component was added by bending the plate according to the valgus present and a derotation component was added before fixation to correct the excessive anteversion if required. (Fig. 1)

An acetabular roofing procedure was performed as described by Pemberton and excised femoral bone for shortening or iliac crest was used as a graft. (Fig. 2)

After relocating the femoral head into the cleared acetabulum the redundant capsule was excised and capsulorrhaphy was performed. The fascia, subcutaneous tissue and skin were closed in layers.

Post-operatively, the hips were immobilized in a hip spica for 3 months. Later check radiographs were taken and based on the congruity and stability of the joint, gradual range of motion exercises and progressive weight bearing walking were advised.

Table 1: DDH types according to tonnis criteria. ${ }^{4}$

\begin{tabular}{|c|c|}
\hline \multicolumn{2}{|r|}{ Grade } \\
\hline I & $\begin{array}{l}\text { Capital femoral epiphysis medial to Perkins } \\
\text { line }\end{array}$ \\
\hline II & $\begin{array}{c}\text { Capital femoral epiphysis medial to Perkins } \\
\text { line, but below the level of the superior } \\
\text { acetabular rim }\end{array}$ \\
\hline III & $\begin{array}{r}\text { Capital femoral epiphysi } \\
\text { superior acetab }\end{array}$ \\
\hline IV & $\begin{array}{l}\text { Capital femoral epiphysis above the level of } \\
\text { the superior acetabular rim }\end{array}$ \\
\hline
\end{tabular}

Table 2: Severin criteria for evaluation of radiographic results. $^{6}$

\begin{tabular}{|l|c|}
\hline Type I & Normal hips \\
\hline Type II & $\begin{array}{c}\text { Concentric reduction of the joint } \\
\text { with deformity of the femoral } \\
\text { neck, head or acetabulum }\end{array}$ \\
\hline Type III & $\begin{array}{c}\text { Dysplastic hips without } \\
\text { subluxation }\end{array}$ \\
\hline Type IV & Subluxation \\
\hline Type V & $\begin{array}{c}\text { The head articulating with a } \\
\text { secondary acetabulum in the } \\
\text { upper part of the original } \\
\text { acetabulum. }\end{array}$ \\
\hline Type VI & Redislocation \\
\hline
\end{tabular}

Table 3: McKay's criteria for clinical evaluation of results. 5

\begin{tabular}{|l|c|c|}
\hline Grade & Rating & Description \\
\hline I & Excellent & $\begin{array}{c}\text { Painless, stable hip; no } \\
\text { limp; more than 15 } \\
\text { degrees of internal } \\
\text { rotation }\end{array}$ \\
\hline II & Good & $\begin{array}{c}\text { Painless, stable hip; } \\
\text { slight limp or decreased } \\
\text { motion; negative } \\
\text { Trendelenburg's sign }\end{array}$ \\
\hline III & Fair & $\begin{array}{c}\text { Minimum pain; moderate } \\
\text { stiffness; positive } \\
\text { Trendelenburg's sign }\end{array}$ \\
\hline IV & Poor & Significant pain \\
\hline
\end{tabular}




\section{Results}

All the cases were followed up at regular intervals with a mean follow up was 15.14 months. In this series the age of the patients ranged from 25 to 96 months with a mean age of 66.86 months.

Out of 21 patients, $7(33 \%)$ were males and 14 (67\%) were females. Right hip was affected in 11 (52\%) patients and left hip in 10 (48\%) patients.

Preoperatively $7(33.33 \%)$ patients had shortening ranging between $0.1-1.0 \mathrm{~cm}, 7(33.33 \%)$ patients had a range between $1.1-2.0 \mathrm{~cm}$ and the other $7(33.33 \%)$ patients had a range between 2.1-3.0 cm. Postoperatively, $12(57 \%)$ patients had no limb length discrepancy, 6 (29\%) patients had limb length discrepancy ranging between $0.1-0.5 \mathrm{~cm}$ and $3(14 \%)$ patients had limb length discrepancy between 0.6-1.0 $\mathrm{cm}$.

Pre operatively the dysplastic hips were graded according to the Tonnis system of grading. 4 (19\%) patients were under grade II, 5 (24\%) patients under grade III and $12(57 \%)$ patients under grade IV.

Of the 21 cases included in the study, open reduction, varus derotation osteotomy and acetabuloplasty of pemberton in $5(24 \%)$ patients (case 1 ); open reduction and acetabuloplasty of pemberton were performed in $9(43 \%$ ) patients (case 2); open reduction, varus derotation osteotomy, femoral shortening and acetabuloplasty of pemberton in 7 (33\%) patients (case 3)
The acetabular index (AI) was measured preoperatively and postoperatively at each follow up visit. It was improved in all the patients at the time of final evaluation. The mean preoperative AI was 44 degrees. At the end of the follow up it was reduced to a mean value of 19.60 degrees.

Femoral neck shaft angle is also assessed preoperatively in this study. It was mainly intended to evaluate the result of varus derotation osteotomy which was performed as a part of the surgery in 12 cases. The average preoperative femoral neck shaft angle was 144 degrees and the average postoperative neck shaft angle is 134 degrees.

Center edge angle (CEA) improved in all patients at the end of follow up except 1 patient who had a redislocation. CEA was negative in all patients preoperatively. The mean CEA postoperatively was 22.9 degrees.

Functional evaluation with modified McKay's criteria segregated the patients into 4 grades. $8(38 \%)$ patients were under grade I (excellent), 11(52\%) patients were under grade II (good), 1(5\%) patient was grade III (fair) and 1 (5\%) was grade IV (poor).

Radiological evaluation using severin's classification system grouped the 21 patients in this study group into 6 classes. $4(19 \%)$ patients were under class I (excellent), 15 (71\%) patients were under class II (good), 1 (5\%) patient under class III (fair) and 1(5\%) patient under class VI (poor).

Table 4: Demographic data and results

\begin{tabular}{|c|c|c|c|c|c|c|c|c|c|c|c|c|}
\hline Case & Age & Sex & Hip & $\begin{array}{l}\text { Short- } \\
\text {-ening }\end{array}$ & $\begin{array}{l}\text { Tonnis } \\
\text { Grade }\end{array}$ & $\begin{array}{c}\text { Preop } \\
\text { AI }\end{array}$ & Procedure & $\begin{array}{c}\text { Follow } \\
\text { Up }\end{array}$ & $\begin{array}{c}\text { Postop } \\
\text { AI }\end{array}$ & $\begin{array}{c}\text { Postop } \\
\text { CEA }\end{array}$ & Mckays & Severins \\
\hline 1 & 38 & $\mathrm{~F}$ & RT & 1.7 & IV & 48 & $\mathrm{OR}+\mathrm{VDO}+\mathrm{PB}$ & 24 & 20 & 30 & Excellent & $\mathrm{I}$ \\
\hline 2 & 52 & $\mathrm{M}$ & RT & 1 & II & 38 & $\mathrm{OR}+\mathrm{PB}$ & 21 & 19 & 24 & Good & II \\
\hline 3 & 76 & $\mathrm{M}$ & RT & 2.8 & IV & 42 & $\mathrm{OR}+\mathrm{VDO}+\mathrm{FS}+\mathrm{PB}$ & 21 & 18 & 30 & Excellent & I \\
\hline 4 & 27 & $\mathrm{M}$ & RT & 1 & III & 39 & OR+VDO+PB & 24 & 22 & 20 & Excellent & $\mathrm{I}$ \\
\hline 5 & 91 & $\mathrm{~F}$ & LT & 1.2 & III & 48 & $\mathrm{OR}+\mathrm{PB}$ & 18 & 24 & 17 & Good & II \\
\hline 6 & 85 & $\mathrm{M}$ & RT & 2.6 & IV & 45 & $\mathrm{OR}+\mathrm{VDO}+\mathrm{FS}+\mathrm{PB}$ & 24 & 17 & 28 & Excellent & II \\
\hline 7 & 74 & $\mathrm{~F}$ & LT & 2.2 & IV & 47 & OR+VDO+FS+PB & 21 & 18 & 25 & Excellent & II \\
\hline 8 & 25 & $\mathrm{~F}$ & LT & 1 & II & 45 & \begin{tabular}{|c|}
$\mathrm{OR}+\mathrm{PB}$ \\
\end{tabular} & 12 & 17 & 28 & Good & II \\
\hline 9 & 56 & $\mathrm{M}$ & $\mathrm{LT}$ & 1.6 & IV & 48 & $\mathrm{OR}+\mathrm{VDO}+\mathrm{PB}$ & 18 & 17 & 20 & Good & II \\
\hline 10 & 54 & $\mathrm{~F}$ & LT & 1 & III & 45 & $\mathrm{OR}+\mathrm{PB}$ & 15 & 23 & 18 & FAIR & II \\
\hline 11 & 54 & $\mathrm{~F}$ & RT & 1.2 & IV & 35 & $\mathrm{OR}+\mathrm{PB}$ & 15 & 22 & 25 & Excellent & II \\
\hline 12 & 88 & $\mathrm{~F}$ & RT & 1.3 & IV & 45 & \begin{tabular}{|l|}
$\mathrm{OR}+\mathrm{PB}$ \\
\end{tabular} & 3 & 28 & & Poor & VI \\
\hline 13 & 87 & $\mathrm{~F}$ & $\mathrm{LT}$ & 2.4 & IV & 38 & $\mathrm{OR}+\mathrm{VDO}+\mathrm{FS}+\mathrm{PB}$ & 12 & 18 & 27 & Excellent & II \\
\hline 14 & 85 & $\mathrm{~F}$ & LT & 1.8 & IV & 42 & OR+VDO+PB & 24 & 18 & 28 & Excellent & $\mathrm{I}$ \\
\hline 15 & 91 & $M$ & LT & 1 & II & 45 & $\mathrm{OR}+\mathrm{PB}$ & 21 & 20 & 14 & Good & III \\
\hline 16 & 85 & $\mathrm{~F}$ & RT & 2.2 & III & 48 & $\mathrm{OR}+\mathrm{VDO}+\mathrm{FS}+\mathrm{PB}$ & 9 & 18 & 28 & Good & II \\
\hline 17 & 86 & $\mathrm{~F}$ & LT & 2 & IV & 45 & $\mathrm{OR}+\mathrm{VDO}+\mathrm{FS}+\mathrm{PB}$ & 9 & 17 & 30 & Good & II \\
\hline 18 & 26 & $\mathrm{M}$ & $\mathrm{LT}$ & 1 & III & 45 & \begin{tabular}{|c|}
$\mathrm{OR}+\mathrm{PB}$ \\
\end{tabular} & 6 & 20 & 18 & Good & II \\
\hline 19 & 87 & $\mathrm{~F}$ & RT & 1.2 & IV & 50 & $\mathrm{OR}+\mathrm{VDO}+\mathrm{PB}$ & 6 & 18 & 28 & Good & II \\
\hline 20 & 50 & $\mathrm{~F}$ & RT & 1 & II & 42 & $\mathrm{OR}+\mathrm{PB}$ & 6 & 20 & 20 & Good & II \\
\hline 21 & 87 & $\mathrm{~F}$ & LT & 3 & IV & 40 & $\mathrm{OR}+\mathrm{VDO}+\mathrm{FS}+\mathrm{PB}$ & 9 & 18 & 22 & Good & II \\
\hline
\end{tabular}

$\mathrm{AI}=$ Acetabular Index

$\mathrm{OR}=$ Open Reduction

VDO= Varus Derotation Osteotomy

$\mathrm{PB}=$ Pemberton's acetabulopalsty

$\mathrm{FS}=$ Femoral Shortening 
$\mathrm{CEA}=$ Centre Edge Angle

\section{Statistical Analysis}

Relation between the obtained values in comparision to the preoperative values; calculated by paired Student $\mathbf{t}$ test: Acetabular index (AI) improved in all hips at final evaluation. The mean preoperative acetabular index was 44 degrees. At the end of follow up it was 19.6 degrees and there was statistically significant difference between the preoperative AI and that at the final evaluation $(t=21.93, p<0.00001)$. Center edge angle (CEA) improved in all patients at the end of follow up except one patient where the femoral head was redislocated. Preoperative CE angle was negative in all patients. The mean CE angle postoperatively was 22.9 degrees and there was statistically significant difference between the preoperative angle and that at the final evaluation $(t=14.66, p<0.00001)$

Relation between various parameters and the final outcome variables; calculated by the Chi-square (x2) test: Preoperative Tonnis grade had no statistically significant effect on the final radiological outcome ( $\mathrm{x} 2=6.08, \quad \mathrm{p}=0.4138)$. Postoperative AI had a statistically significant effect on the final radiological outcome ( $\mathrm{x} 2=25.31, \mathrm{p}=0.0026)$. Postoperative $\mathrm{CE}$ angle had a statistically significant effect on the final radiological outcome ( $\mathrm{x} 2=23.15, \mathrm{p}=0.0007)$.

The Age had no statistically significant effect on the final clinical outcome when the patients were divided into multiple groups based on age (x2 $=9.79$, $\mathrm{p}=0.6341$ ). The final clinical outcome also was not significantly affected by $\operatorname{sex}(\mathrm{x} 2=1.11, \mathrm{p}=0.7751)$, side of the hip ( $\mathrm{x} 2=3.28, \mathrm{p}=0.3507)$, and by the amount of shortening $(\mathrm{x} 2=6.47, \mathrm{p}=0.3719)$.

\section{Discussion}

Neonatal hip screening will not completely eliminate the problem of delayed diagnosis of developmental dysplasia of hip. There will be patients who reach the walking age with developmental dysplasia of hip (DDH), either secondary to delayed diagnosis or failed primary treatment. ${ }^{7,8}$ We found that the cases of DDH still present late. In our study of 21 patients only $5(24 \%)$ patients were diagnosed before the age of one year, the walking age according to the history.

After diagnosis, management of DDH in this age group is mainly surgical. Treatment varies from open reduction alone or with combined pelvic and femoral osteotomies. The main aim of the surgeon is to achieve a stable concentric reduction. Open reduction provides a good confirmation of the reduction while causing less injury to the femoral head as compared to closed reduction and an opportunity to assess the amount of acetabular dysplasia. ${ }^{9}$ In our study, for all the 21 $(100 \%)$ patients open reduction was done as a part of the surgery.
Olney et $\mathrm{al}^{10}$ reported that a one stage procedure was too aggressive, but was considered to be less traumatic for the hip compared to closed reduction and prolonged immobilisation. Therefore several authors suggested a one-stage procedure consisting of open reduction, pelvic osteotomy and femoral osteotomy. ${ }^{11-14}$ Furthermore, several studies describe the treatment of DDH with a one-stage operation in children over two years of age. ${ }^{13,15,16}$ In this study we treated $21(100 \%)$ previously untreated DDH in children from two to eight years with a one stage operative procedure.

Galpin et $\mathrm{al}^{13}$ reported a series of 33 dislocated hips in patients older than two years of age who were treated with a one-stage open reduction, femoral shortening, and pelvic osteotomy. They found satisfactory results clinically in $85 \%$ of hips and 200 radiographically in $75 \%$ cases.

Barrett et $\mathrm{al}^{17}$ reported to have $85 \%$ very good and good results after open reduction and Salter type pelvic osteotomy in patient"s aged between 18 months and 6 years.

Basant kumar Bhuyan ${ }^{18}$ reported 25 patients (30 hips) who underwent one stage triple procedure. The McKayes score was excellent in 13 hips, good in 14 hips, fair in 2 and poor in 1 hip. The severin"s class I and II were found in 25 hips (83.3\%).

El sayed AH Abdulla et al $^{19}$ reported 35 patients(42 hips) in the age group of 18 to 96 months with excellent and good clinical and radiological results in $88 \%$ patients.

In our study at the final evaluation 19 (90\%) patients had excellent and good results both clinically and radiologically. Clinically based on McKay"es criteria the results were excellent 8 (38\%) patients, good $11(52 \%)$ patients, fair $1(5 \%)$ patient and poor 1 (5\%) patient. Radiologically based on Severines classification the results were excellent 4 (19\%) patients, good $15(71 \%)$ patients, fair $1(5 \%)$ patient and poor in $1(5 \%)$ patient.

One patient $(5 \%)$ had redislocation of the hip in our study, this patient had a slightly high postoperative acetabular index (upper limit of normal range) and low center edge angle (lower limit of normal range) in immediate postoperative radiographs. The patient was offered revision open reduction and acetabuloplasty and now has a stable painless hip with good range of motion. Rudolf et al reported 3 of 54 hips with redislocation. Grill ${ }^{20}$ reported 12 of 50 hips with redislocation and resubluxation. The other complication encountered in one patient (5\%) was stiffness of hip, the range of motion has improved on intense monitored physiotherapy.

Limb length discrepancy was noticed postoperatively in $9(43 \%)$ cases. $7(33 \%)$ of these cases had femoral shortening as a part of the surgery. In the other two, one (5\%) had open reduction and Acetabuloplasty which had a redislocation; the other 
case $(5 \%)$ had open reduction, varus derotation osteotomy and acetabuloplasty.

All follow up radiographs were evaluated for signs of avascular necrosis of femoral head. There was no case with the evidence of avascular necrosis. ESAH Abdullah et $\mathrm{al}^{19}$ reported one patient $(2.3 \%)$ in their study with avascular necrosis. Basant kumar Bhuyan ${ }^{18}$ reported $1(5 \%)$ case with evidence of AVN. Ryan et al. reported 11 out of 25 hips (44\%) with avascular necrosis.

\section{Conclusion}

We conclude from our study that a single stage combined surgical treatment is a good method for management of late presenting developmental dysplastic hips. An open reduction through a wide exposure allowing full assessment along with removal of tissues hindering reduction is necessary for a successful surgery. Proper positioning of the femoral head into the acetabulum is required along with capsulorraphy and correction of acetabular dysplasia is very important for stable concentric reduction of the hip. Femoral shortening should be performed in cases in which a reduction is achieved with difficulty. A well calculated and executed femoral shortening doesn't create a significant limb length discrepancy postoperatively. In femoral osteotomy, derotation component is more required compared to varus component because most cases have excessive femoral neck anteversion. Despite a short follow up period, the results of our study indicate that whatever is the age of the patient, bony procedures on proximal femur and pelvis must be kept in mind while treating late presenting patients with dysplastic hips. The combination of open reduction with pelvic and/ or femoral osteotomy when needed gives good immediate stability and promotes remodelling.

Case 1: 38 Months (3 years 2 months) / Female

Surgery performed: Open reduction + varus derotation osteotomy + pemberton's acetabuloplasty

\section{Preoperative}
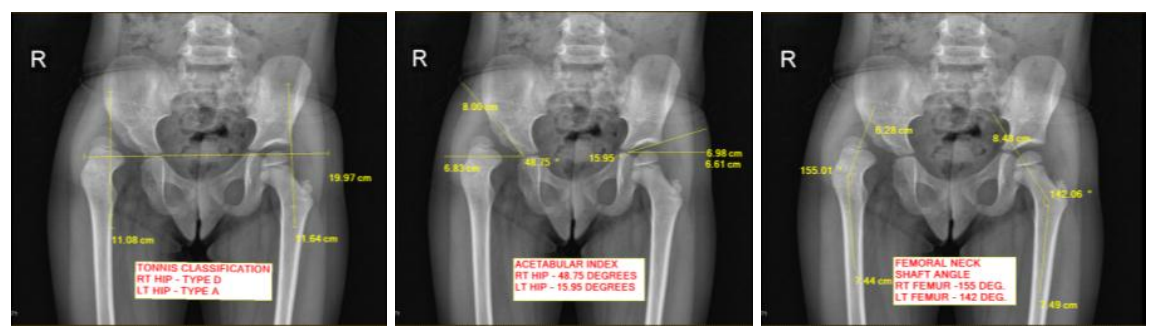

Postoperative

Follow Up AT 24 Months
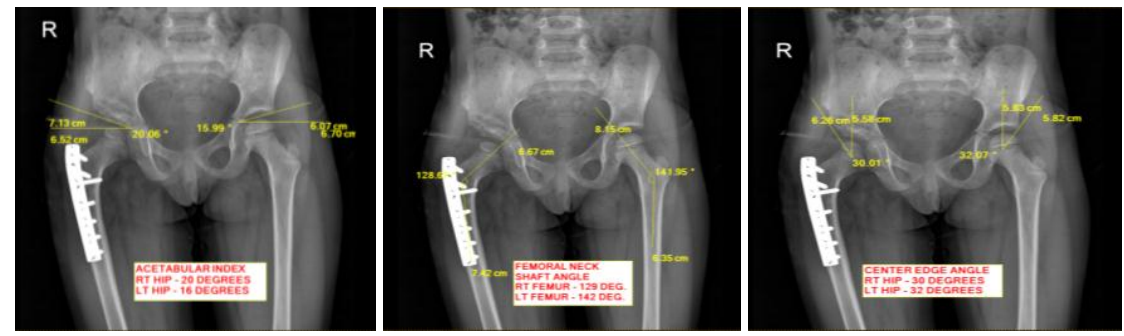

Case 2: 25 Months (2 years 1 month)/ Female

Surgery performed: Open reduction + pemberton's acetabuloplasty

\section{Preoperative Radiograph}

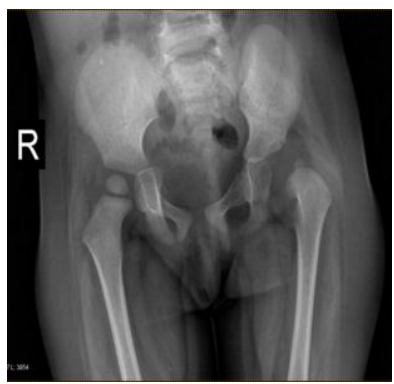

Postoperative Radiograph

Follow up at 12 Months

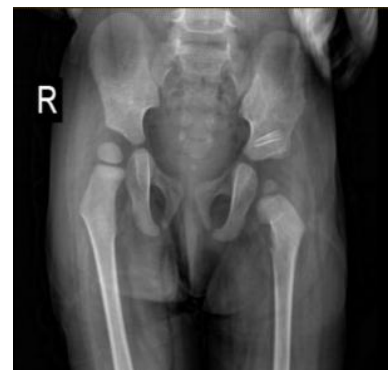


Case 3: 86 Months (7 years 2 months)

Surgery performed: Open reduction + varus derotation osteotomy + femoral shortening + pemberton's acetabuloplasty

\section{Preoperative Radiograph}
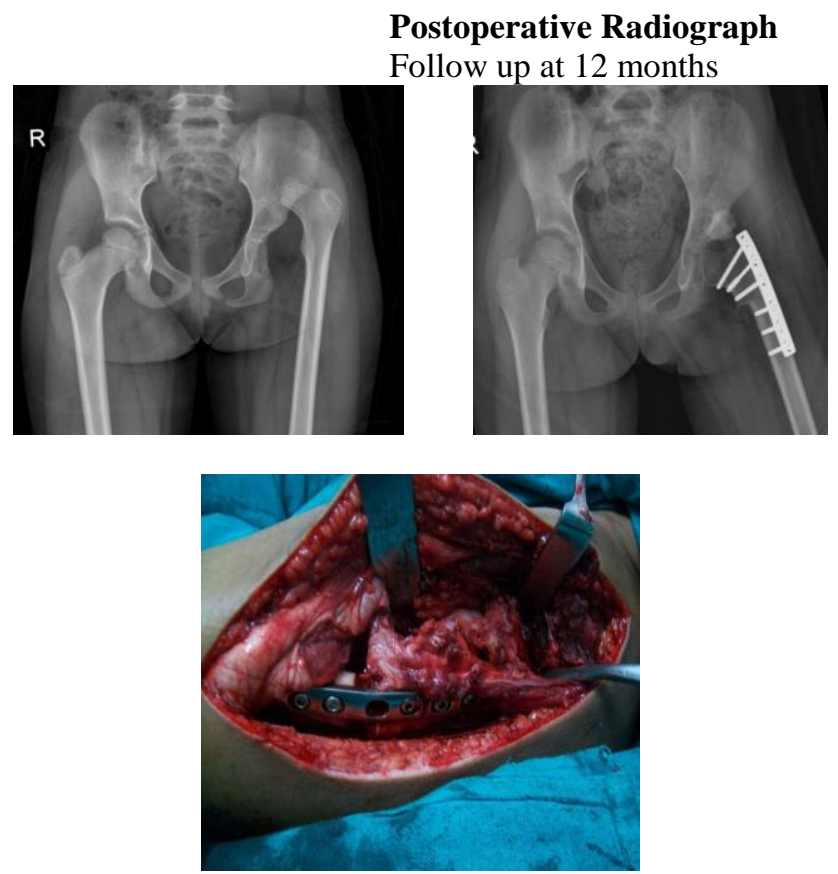

Fig. 1: Femoral shortening with varus derotation osteotomy

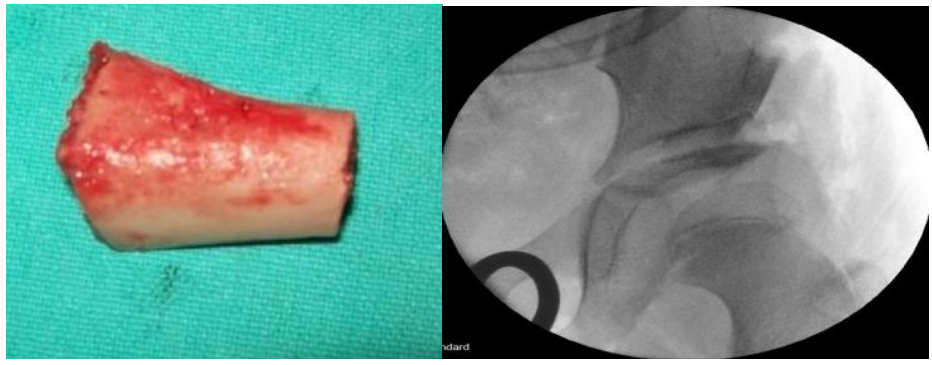

\section{Fig. 2: Femoral graft placed in the osteotomy site}

\section{References}

1. Beaty H. Congenital and developmental dysplasia of the hip. In: Canale T, editor. Cambell's operative orthopaedics. volume $2.9^{\text {th }}$ ed. St Louis, Boston, Chicago, London, Toronto, Baltimore: CV Mosby Company;1998. p. 1079-117.

2. Hart VL. Primary Genetic Dysplasia of the Hip with and without Classical Dislocation. J. Bone and Joint Surg. 1942;24: 4.

3. Specht EE. Congenital Dislocation of the Hip (Medical Progress). West J Med.1976;124:18-28.

4. Tonnis D. Congenital hip dislocation. New York; Thieme-Stratton Inc.;1982.

5. Sharpe P, Mulpuri K, Chan A, Cundy PJ. Differences in risk factors between early and late diagnosed developmental dysplasia of the hip. Arch Dis Child Fetal Neonatal Ed. 2006;91(3):F158-62.

6. Severin E. Contribution to knowledge of congenital dislocation of the hip joint; Late results of closed reduction and arthrography studies of recent cases Acta Chir Scand 1941;84(Suppl 63):1-142.
7. Mackenzie IG, Wilson JG. Problems encountered in the early diagnosis and management of congenital dislocation of the hip. J Bone Joint Surg.1981;63-B: 38-42.

8. Williamson J. Difficulties of early diagnosis and treatment of congenital dislocation in Northern Ireland. J Bone Joint Surg.1972;54-B (1):13-17.

9. Ashly RK, Larsen LJ, James PM. Reduction of dislocation of hip in older children. J Bone Joint Surg Am.1972;54- A:545-550.

10. Olney B, Latz K, Asher M. Treatment of hip dysplasia in children with a combined one-stage procedure. Clin Orthop Relat Res 1998;347:215-223.

11. Dimitriou JK, Cavadias AX. One-stage surgical procedure for congenital dislocation of the hip in older children. Long-term results. Clin Orthop Relat Res 1989;246: 30-38.

12. Forlin E, Munhoz DA, Cunha LA, Figueiredo DC. Treatment of developmental dysplasia of the hip after walking age with open reduction, femoral shortening, and acetabular osteotomy. Orthop Clin North Am 2006;37:149-160.

13. Galpin RD, Roach JW, Wenger DR, Herring JA, Birch JG. One-stage treatment of congenital dislocation of the 
hip in older children, including femoral shortening. J Bone Joint Surg 1989;71-A:734-741.

14. Klisic P, Jankovic L. Combined procedure of open reduction and shortening of the femur in treatment of congenital dislocation of the hips in older children. Clin Orthop Relat Res 1976;119:60-69.

15. Nakamura M, Matsunaga S, Yoshino S. Long-term result of combination of open reduction and femoral derotation varus osteotomy with shortening for developmental dislocation of the hip. Journal of Pediatric Orthopaedics B.2004;13:248-253.

16. Berekely ME, Dickson JH, Cain TE, Donovan MM. Surgical therapy for congenital dislocation of hip in the patients who are twelve to thirty six months old. J Bone and Joint Surg. 1984;66-A:412-420.

17. Barrett WP, Staheli LT, Chew DE. The Effectiveness of the Salter innominate osteotomy in the Treatment of Congenital dislocation of the Hip. J Bone Joint Surg.1986;68-A:1.

18. Bhuyan BK. Outcome of one-stage treatment of developmental dysplasia of hip in older children Indian Journal of Orthopaedics.2012;46:5.

19. Abdullah ESAH. Evaluation of the results of operative treatment of hip dysplasia in children after the walking age. Alexandria Journal of Medicine.2012;48:115-122

20. Grill F. Treatment of hip dislocation after walking age. Arch Orthop Trauma Surg.1984;102:148-53. 